\title{
Análise do consumo de carne suína no município de Dom Pedrito-RS
}

\author{
Lilian Ribeiro Kratz ${ }^{1}$ \\ Bárbara Pinheiro Moreira ${ }^{2}$ \\ Osmar Manoel Nunes ${ }^{3}$ \\ Mariana Rockenbach de Ávila ${ }^{4}$ \\ Shirley Grazieli da Silva Nascimento ${ }^{5}$ \\ Leonardo Paz Deble ${ }^{6}$
}

\begin{abstract}
RESUMO
A carne suína é uma das mais antigas formas de alimentação humana, tendo em vista que a espécie foi domesticada há 5000 a.c., na China e em outras regiões da Ásia. A sua natureza de caráter adaptável, porte e rusticidade permitiram a fácil domesticação, que foi anterior a de outros animais, como por exemplo, os bovinos. O atual estudo tem como base a análise do consumo de carne suína no Brasil, que está abaixo da média mundial e de outros países no ranking de grandes produtores desse alimento. Tendo isso em vista, é possível que haja restrições por parte dos consumidores relacionadas a esse tipo de carne, alguns fatores serão avaliados nesse trabalho, abordando essa problemática. O presente artigo tem como objetivo principal analisar o comportamento dos consumidores e os possíveis fatores que restringem o consumo de carne suína no município de Dom Pedrito, RS. Para o levantamento dos dados, foi utilizado um questionário elaborado no site Survey Monkey, software desenvolvido para coleta de dados em pesquisas. Após aplicação dos questionários, foi possível, através dos dados, elucidar algumas questões sobre o consumo de carne suína em Dom Pedrito, RS, sendo que foi respondido um total de 101 questionários. Após análise e discussão dos dados obtidos, foi possível avaliar que o consumo de carne suína em Dom Pedrito-RS, no grupo de consumidores não é influenciado por possíveis restrições de consumo, tais como, ser um alimento com alto teor de gordura, de difícil digestão entre outros. Mas sim, é consequência do hábito de consumo e influência da cultura local, onde a preferência é dada a outras proteínas, como carne bovina e ovina.

Palavras-Chave: Alimento de origem animal, fonte de proteína, suínos.
\end{abstract}

\section{Analysis of pork consumption in the city of Dom Pedrito, Brazil}

\begin{abstract}
Pork is one of the oldest forms of human food, since the species was domesticated $5000 \mathrm{BC}$ in China and other parts of Asia. Its adaptive nature, size and rusticity allowed for easy domestication, which was earlier than other animals, such as cattle. The current study is based on the analysis of pork consumption in Brazil, which is below the world average and other countries in the ranking of large producers of this food. Considering this, it is possible that there are restrictions on the part of the consumers related to this type of meat, some factors will be evaluated in this work, addressing this problem. The main objective of this article is to analyze the behavior of consumers and the possible factors that restrict pork consumption in the municipality of Dom Pedrito, RS. In order to collect the data, a questionnaire was used in the Survey Monkey site, software developed for data collection in surveys. After applying the questionnaires, it was possible, through the data, to elucidate some questions about pork consumption in Dom Pedrito, RS, and a total of 101 questionnaires were answered. After analyzing and discussing the data obtained, it was possible to evaluate that the pork consumption in Dom Pedrito, RS, in the consumer group is not influenced by possible consumption restrictions, such as being a high fat food, difficult digestion among others. But it is a consequence of the habit of consumption and strong influence of the local culture, where preference is given to other proteins such as beef and sheep.
\end{abstract}

Keywords: Food of animal origin, protein source, pigs.

\footnotetext{
${ }^{1}$ Doutora em Zootecnia. Professora Adjunta na UNIPAMPA, Campus Dom Pedrito.

${ }^{2}$ Zootecnista. Mestranda em Ciências Biológicas na UNIPAMPA, Campus São Gabriel.

${ }^{3}$ Doutor em Desenvolvimento Regional. Professor Adjunto na UNIPAMPA, Campus Dom Pedrito.

${ }^{4}$ Doutora em Zootecnia. Pesquisadora Visitante, Embrapa Clima Temporado, Pelotas, Rio Grande do Sul.

${ }^{5}$ Doutora em Sistemas de Produção Agrícola Familiar. Professora Adjunta na UNIPAMPA.

${ }^{6}$ Doutor em Ciências Florestais. Coordenador Acadêmico e Professor Adjunto na Universidade Federal do Pampa (UNIPAMPA).
} 


\section{INTRODUÇÃO}

Atualmente os consumidores estão mais atentos as questões da composição nutricional dos alimentos e buscam constantemente uma dieta que atenda às necessidades do dia-a-dia e que seja considerada saudável (BAKER, 1998; REGMI, 2001). Existe uma busca por melhor compreensão e histórico dos produtos adquiridos que estão sendo consumidos (SANTOS; AURÉLIO, 2013). Evidencia-se atenção especial as proteínas de origem animal, onde há uma preocupação com o bem-estar animal e rastreamento dos mesmos, tanto que, as propriedades rurais adotaram manejos e métodos que atendam as expectativas em relação à qualidade do produto sem descuidar da qualidade de vida dos animais (MONTOSSI et al., 2018).

Tendo isso em vista, foram formados grupos de pessoas com esclarecimento sobre os alimentos que consomem e sua origem, não permitindo margem para crenças ou empirismo sobre produtos. Como exemplo disso apontamos a carne suína, que em diversos trabalhos aparece como sendo pouco consumida por ser considerada gordurosa (FARIA et al., 2006), de difícil digestão, ou passível de transmitir doenças, sendo que nenhuma dessas teorias foi comprovada cientificamente e inclusive em alguns desses estudos entende-se que essas ideias foram passadas de uma geração para outra ou através de conhecimento do senso comum (BUSO, 2000).

A carne é um alimento de importância simbólica (FLANDRIN, J; MONTANARI, 1998), que além de historicamente ter auxiliado o desenvolvimento dos seres humanos durante o período de caça, também gerou certa hierarquia social. Trata-se de uma das melhores fontes de proteína disponíveis para o ser humano. A carne suína está entre as carnes mais consumidas no mundo (DAVIS; LIN, 2005), estima-se que seja primeira espécie domesticada para fins produtivos, principalmente pela sua rusticidade e adaptabilidade. No Brasil, a produção de suínos evoluiu nos últimos anos, tanto em produção quanto exportação.

Destaca-se que são poucos os estudos sobre o consumo de carne suína no município de Dom Pedrito, Rio Grande do Sul (RS). Tendo isso em vista, oberva-se a necessidade de realizar pesquisas para esclarecer a opinião dos consumidores no tocante ao tema. Pesquisar sobre o consumo de carne suína, torna-se relevante para a cadeia produtiva e para o comercio desse produto. Resalta-se que o consumo de carne suína no Brasil, ainda está abaixo da média mundial. Portanto, é possível que haja restrições por parte dos consumidores brasileiros relacionadas a essa fonte de proteína e alguns fatores relacionados a esta temática serão 
avaliados nesse trabalho, abordando essa problemática em um grupo restrito de consumidores no município de Dom Pedrito, RS.

Desta forma, este estudo objetiva responder às seguintes indagações: a) quais são os fatores que influenciam e/ou restringem o consumo de carne suína no município de Dom Pedrito, RS, na opinião de um grupo seleto de consumidores? Para responder este problema, identificou-se como objetivo principal, verificar o comportamento do consumidor de carne suína e os possíveis fatores que podem restringem o consumo desta, e como objetivos específicos analisar o comportamento do consumidor e determinar quais são os principais fatores de restrição ao consumo de carne suína.

\section{REFERENCIAL TEÓRICO}

A carne é um alimento de importância simbólica na história da raça humana. De acordo com hipóteses antropológicas, a mudança para um clima mais seco há cerca de cinco milhões de anos provocou a diminuição de florestas na África oriental, aumento das savanas e, com isso, restrição de recursos vegetais, forçando ancestrais humanos a se adaptarem, consumindo mais carne e formando grupos organizados para caçadas (MAGNONI; PIMENTEL, 2007). Isto, por consequência, teria levado ao desenvolvimento da comunicação, das capacidades intelectuais, divisão de tarefas por sexo, estimulando a organização social e familiar tipicamente humana (FRANDRIN, 1998). A carne suína é uma das mais antigas formas de alimentação, tendo em vista que a espécie foi domesticada há 5000 a.C., na China e em outras regiões da Ásia. A sua natureza de caráter adaptável, porte e rusticidade permitiram a fácil domesticação, que foi anterior a de outros animais, como os bovinos (Associação Brasileira de Proteína Animal, 2017).

O Brasil é o quarto maior produtor e exportador de carne suína no mundo, sendo superado em produção pela China, União Europeia e Estados Unidos, e em exportação pela União Europeia, Estados Unidos e Canadá (ABPA, 2016). Quanto à produção interna, o sul do país (Santa Catarina, Paraná e Rio Grande do Sul) detém aproximadamente 65\% da produção, e os principais estados exportadores são Santa Catarina e Rio Grande do Sul que contribuíram com 35,05\% (194 milhões toneladas) e 33,11\% (183 milhões toneladas), respectivamente (ABPA, 2016).

Conforme a Associação Brasileira de Proteína Animal, em 2015 o país produziu um total de 3.643 milhões de toneladas sendo que $85 \%$ foram destinados ao consumo interno e exportados apenas $15 \%$. Entre os maiores consumidores de carne suína do país, estão os estados 
mais ao sul, no Rio Grande do Sul, por exemplo, o consumo chegou a 22,9 $\mathrm{kg}$ por pessoa em 2015 (PRESS AGROBUSINESS, 2015) enquanto a média brasileira de consumo não ultrapassa $15 \mathrm{~kg}$ per capita (MARÇAL et al., 2016). Considerando ainda que não é apenas no Brasil que a carne suína não é a preferência, países vizinhos apresentam o mesmo panorama, como os uruguaios que consomem aproximadamente $14 \mathrm{~kg}$ per capta de carne suína, enquanto os argentinos em torno de $11 \mathrm{~kg}$ e ambos consumem maior quantidade de carne bovina, seguida de carne de frango e em terceiro lugar carne suína (ABAG, 2015).

No Brasil não existem muitas informações referentes à opinião da população sobre carne suína, mas alguns trabalhos demonstram que existe certa rejeição a essa proteína, além desse fato constata-se baixo consumo quando comparado a outros países. Tendo isso em vista esse trabalho tem como finalidade aprofundar o debate sobre possíveis restrições ao consumo de carne suína, detalhando os fatores que influenciam sua comercialização.

O marketing pondera que o comportamento do consumidor é extremamente influenciado por características individuais culturais, sociais, pessoais e psicológicas (KOTLER; ARMSTRONG, 2003). A escolha pelo alimento é especificamente determinada por fortes e complexos fundamentos sociais e econômicos que revelam a importância do ato de se alimentar não somente para a nutrição dos tecidos (MAGNONI; PIMENTEL, 2007). Considerando tais peculiaridades existem fatores avaliados como pontos fortes e fracos na carne suína, de acordo com Roppa (1996) o seu sabor é o principal atributo que leva ao seu consumo, enquanto e ideia de que a carne possa fazer mal e/ou possua altos índices de colesterol, influencia negativamente a sua comercialização.

Informações semelhantes foram descritas por Bezerra et al (2007) que em seu estudo demonstra que na opinião pública, persistem mitos de que a carne suína é muito gordurosa, com alto nível de colesterol e de difícil digestão, tais conceitos são transmitidos de geração para geração, sem bases científicas.

Essa teoria se deve ao fato da carne suína ser associada ao modo de criação obsoleto. Por desconhecimento, muitos deixam de consumi-la acreditando que os suínos são criados em meio à lama, consumindo restos de alimentos e impurezas, tal fato não se confirma, tendo em vista que a suinocultura evoluiu consideravelmente não só se tratando de manejo e sistema de criação, mas em melhoramento genético, deixando de ser um animal com grandes camadas de gordura sobre o músculo para obter o que hoje gira em torno de $1,1 \mathrm{~cm}$ à $3,5 \mathrm{~cm}$ de espessura de toucinho, e carne magra. 
O consumo exacerbado de lipídios é uma preocupação da população em geral, tendo em vista que pode ocasionar doenças cardíacas, esses problemas de saúde estão entre as principais causas de morte no Brasil. Os consumidores estão cientes disso, considerando que cada vez mais buscam alimentação saudável, objetivando longevidade e qualidade de vida (FARIA et al., 2006).

Isso impacta o consumo de carne suína porque muitos brasileiros citam a proteína como gordurosa e com altos teores de colesterol. Entretanto essa ideia é equivocada, analisando que já existem trabalhos comparando a qualidade nutricional das carnes de suínos, frangos e bovinos. Um desses trabalhos avaliou justamente os teores de lipídios, proteínas e calorias (Tabela 1) e evidenciou que não existem diferenças consideráveis entre os três tipos de carnes (MARÇAL et al., 2016). Na Tabela 01 abaixo é possível verificar a composição centesimal de alimentos de origem animal, incluindo bovinos, suínos e frangos.

Tabela 01- Composição centesimal de carne suína, bovina e de frango

\begin{tabular}{lllll}
\hline Carnes & Lipídios (\%) & Proteína (\%) & $\begin{array}{l}\text { Colesterol } \\
(\mathrm{mg} / 100 \mathrm{~g})\end{array}$ & Valor Calórico (kcal) \\
\hline Suína (pernil) & $1,27 \pm 0,51$ & $21,32 \pm 0,19$ & $56,97 \pm 5,25$ & $96,69 \pm 4,64$ \\
Bovina (alcatra) & $2,03 \pm 0,62$ & $22,65 \pm 0,11$ & $60,96 \pm 1,91$ & $108,97 \pm 5,29$ \\
Frango (coxa/sobrecoxa) & $3,27 \pm 0,80$ & $18,91 \pm 0,37$ & $75,94 \pm 1,18$ & $105,07 \pm 6,26$ \\
\hline
\end{tabular}

Fonte: Adaptado de Hautrive et al. (2012).

Com essas informações é possível afirmar que um dos principais fatores de restrição de consumo da carne suína é a falta de informação. Os consumidores desconhecem a composição nutricional da proteína em estudo e por informações obtidas de maneira empírica deixam de consumi-la, sobretudo pessoas com pouco acesso a informação.

O município pesquisado, Dom Pedrito, ocupa uma área de aproximadamente $5.227 \mathrm{~km}^{2}$, situado na fronteira sudoeste do Rio Grande do Sul, reconhecido no estado como "Capital da Paz" com cerca de 40 mil habitantes (JORGE; SLONGO, 2001).

Dom Pedrito apresenta como principal atividade econômica a pecuária e agricultura, com enfoque maior no cultivo de arroz e soja. No que diz respeito à pecuária, existem criatórios de renome, conhecidos nacional e internacionalmente. Tendo isso em vista, é da cultura da região o consumo frequente de carne bovina e também forte apreciação de carne ovina (JORGE; SLONGO, 2001). 


\section{MATERIAL E MÉTODOS}

Para levantamento dos dados, foi utilizado um questionário elaborado no site Survey Monkey, software desenvolvido para realização de pesquisas como ferramentas de coleta de dados. O questionário foi constituído de 20 (vinte) questões com lógica de perguntas, ou seja, conforme a resposta o entrevistado era desclassificado ou designado à próxima pergunta e/ou a seguir respondendo.

Para coleta de dados, foi disponibilizado um link para acesso ao questionário, que foi compartilhado em redes sociais (Facebook, Linked In), em meios de comunicação (Whats App) e via E-mails. O público alvo foi composto de indivíduos residentes em Dom Pedrito, RS, bem como consumidores de carne suína.

O link para acesso ao questionário ficou disponível por 20 (vinte) dias, após isso foi feita analise descritiva através de método qualitativo, com uma margem de erro de $10 \%$ (dez) e confiabilidade de $90 \%$.

Conforme Triviños (1987) a pesquisa descritiva exige do investigador uma série de informações sobre o que deseja pesquisar. Esse tipo de estudo pretende descrever os fatos e fenômenos de determinada realidade.

A pesquisa qualitativa não se preocupa com representatividade numérica, mas com o aprofundamento da compreensão de um grupo social, de uma organização. Conforme Goldenberg (1997) os pesquisadores qualitativos recusam o modelo positivista aplicado ao estudo da vida social, uma vez que o pesquisador não pode fazer julgamentos nem permitir que seus preconceitos e crenças contaminem a pesquisa. As características da pesquisa qualitativa são: objetivação do fenômeno; hierarquização das ações de descrever, compreender, explicar, precisão das relações entre o global e o local em determinado fenômeno (GERHARDT, 2009).

Desta forma, utilizou-se para determinar a amostra a ser coletada a seguinte equação:

\section{$\mathrm{nO}=1 / \mathrm{E} 02$}

Onde:

- n0 é uma primeira aproximação para o tamanho da amostra;

- E0 é o erro amostral tolerável.

Devido ao elevado tamanho da população em questão, corrigiu-se a fórmula para:

$$
(n=n o): n=(N * n 0) / N+n 0
$$

Onde:

- N é o tamanho da população;

- n é o número de elementos da amostra. 
Dessa forma, para um erro amostral de $10 \%$ e a população do município de Dom (38.898 mil habitantes) temos que:

\section{n0 $=1 /$ E02}

Onde:

- $\mathrm{n} 0=1 /(0,1) 2 \mathrm{n} 0=1 / 0,01=100$

- $\mathrm{n}=(38898 * 100) /(38898+100)=34773800 / 347838=\mathbf{9 9 , 7}$.

Assim, definiu-se que a amostra com estas características deveria captar a opinião de no mínimo 100 (cem) entrevistados.

\section{RESULTADOS E DISCUSSÃO}

Após aplicação dos questionários e análise dos dados já tabulados pelo sistema, foi possível elucidar algumas questões sobre o consumo de carne suína no município de Dom Pedrito, RS, os quais implicaram na ideia inicial de avaliar possíveis fatores restritivos quanto ao consumo desse alimento, e hierarquização dos mesmos, caso existentes. Do total dos entrevistados 101 (cento e um) indivíduos, 14,85\% foram desclassificados por declararem não serem consumidores de carne suína. Tendo essas questões em vista, as análises foram calculadas com base no total de 86 (oitenta e seis) respondentes, ou seja, $81,19 \%$ do total de respondentes.

O grupo pesquisado é formado principalmente por respondentes que possuem nível superior ou pós-graduação em $70 \%$ da amostra, com faixa etária entre 21 à 39 anos de idade. $\mathrm{O}$ que caracteriza um grupo jovem e instruído, que possivelmente não possui crenças sobre o consumo da carne suína no que tange fazer mal a saúde ou ser gordurosa demasiadamente devido ao conhecimento empírico, considerando que possivelmente conhecem de alguma maneira o ciclo produtivo e manejo sanitário dos suínos ou possuem acesso para obter tal conhecimento, sendo suas respostas pautada com base no conhecimento.

Nas primeiras questões foram abordadas caraterísticas básicas, tais como, sexo, idade e ocupação, objetivando classificar identificar os grupos de consumidores. Dos entrevistados $51,16 \%$ são do sexo feminino e $48,84 \%$ do sexo masculino, e a maior representatividade etária foi entre 21 a 29 anos com 32,56\%, seguido daqueles que apresentam entre 30 a 39 anos com um percentual de 25,58\%, seguido daqueles que estão entre 40 a 49 com 19,77\%, os que possuíam entre 50 a 59 que representam 16,28\%, com 60 ou mais representaram 3,49\% e aqueles de 18 a 20 e com 17 ou menos, exibem o mesmo percentual de 1,16\%. 
Pode-se destacar que a maioria dos entrevistados é do sexo feminino, lembrando que na sociedade tradicional, como a de Dom Pedrito, geralmente é responsável pela aquisição e realização de compras de supermercados. Também pode-se notar que entre 21 e 60 anos representa um percentual de $94.19 \%$ dos entrevistados. Estes dados deixam claro que a amostra respondente é madura suficiente para avaliar de maneira concisa sobre o consumo de carne suína no município de Dom Pedrito, RS. Os dados apresentados podem ser verificados na Figura 01, que ilustra a faixa etária dos consumidores participantes desta pesquisa.

Figura 01- Faixa etária dos consumidores respondentes sobre consumo de carne suína em Dom Pedrito.

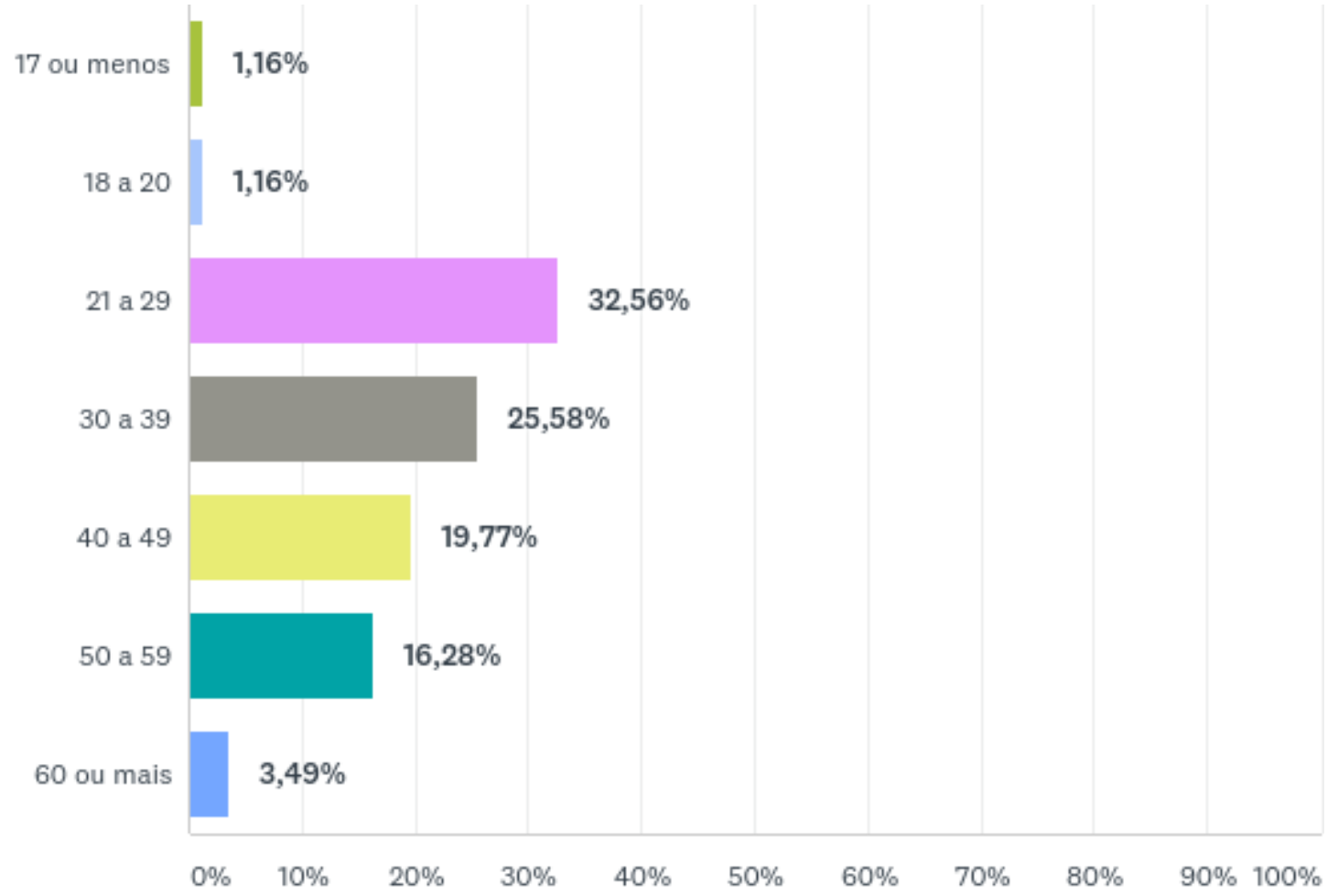

Fonte: Adaptado de Survey Monkey.

Quando se perguntou sobre a escolaridade dos respondentes, mais da metade dos respondentes possuem nível superior ou pós-graduação (em andamento ou concluído) representando $35,29 \%$ cada, somando um total de 70,58\%, enquanto os demais possuem com ensino médio $17,65 \%$, ensino técnico $7,06 \%$ e ensino fundamental $4,71 \%$, conforme pode ser observado na Tabela 02 , abaixo. 
Tabela 02- Faixa etária dos consumidores pesquisados.

\begin{tabular}{|l|l}
\hline Opções de resposta & Respostas \\
\hline Ensino fundamental (1) & $4,71 \%$ \\
\hline Ensino médio (2) & $17,65 \%$ \\
\hline Ensino técnico (3) & $7,06 \%$ \\
\hline Ensino superior (4) & $35,29 \%$ \\
\hline Pós-graduação (5) & $35,29 \%$ \\
\hline
\end{tabular}

Fonte: Adaptado de Survey Monkey.

Ainda sobre os consumidores pesquisados, a maioria relatou como ocupação ser funcionário no setor público totalizando $33,72 \%$, trabalhadores do setor privado 19,77\%, estudantes 17,44\%, setor agropecuário 11,63\%, domésticos (as) e autônomos representam $6,98 \%$ (totalizando $13,96 \%$ ), aposentados $5,81 \%$ e por último, desempregados com $4,65 \%$ dos respondentes.

Após a identificação das características dos consumidores que participaram do questionário, passou-se a abordar questões diretas ao objeto da pesquisa, e buscou-se identificar a preferência por carnes dos consumidores, que podiam classificar de 01 a 05 , sendo 01 o alimento de maior preferência e 05 o de menor preferência.

Figura 02- Preferência de carnes para consumo, conforme respondentes.

Sendo 1 carnes de maior preferência e 5 de menor preferência.

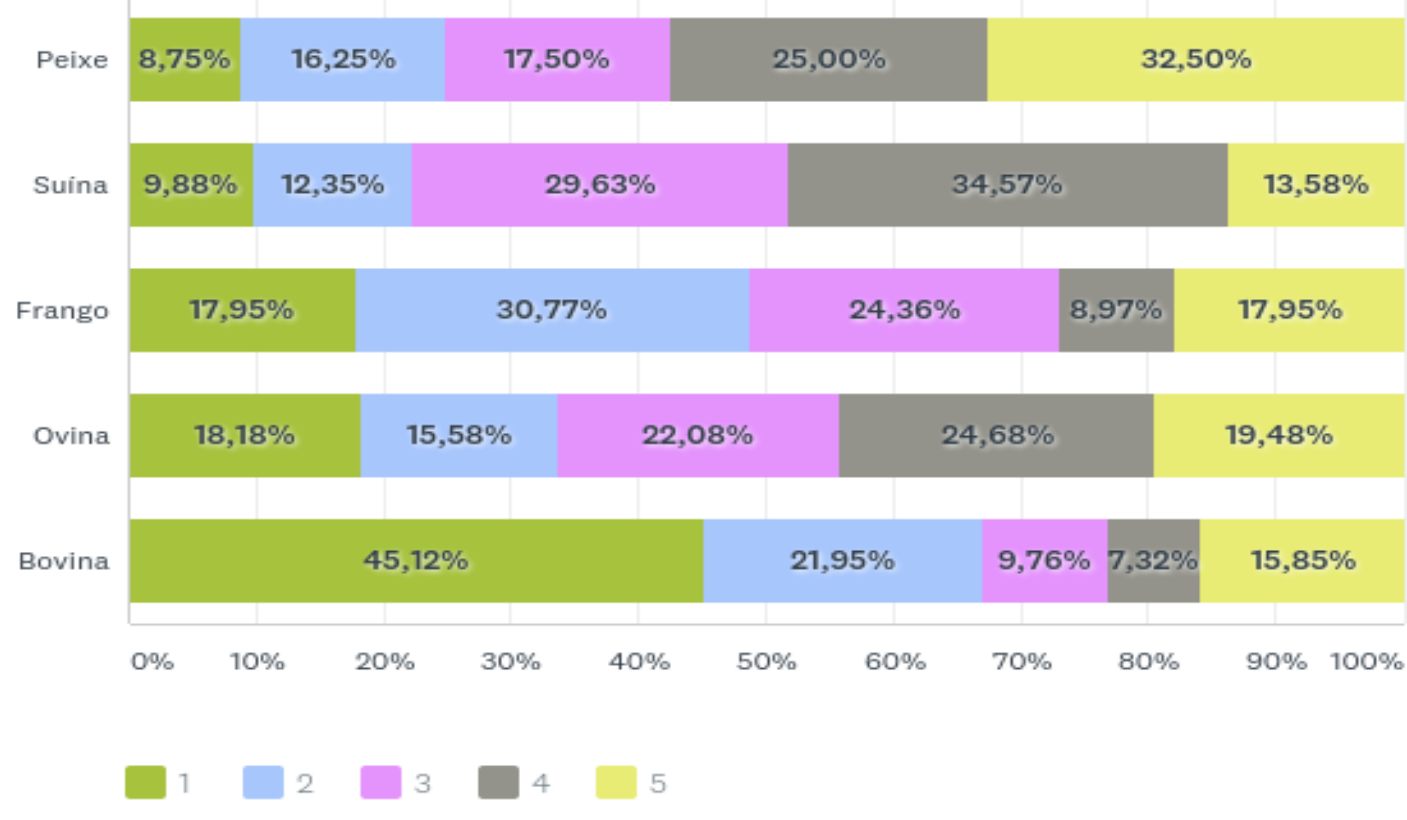

Fonte: Adaptado de Survey Monkey. 
Considerando o diferencial da região, já que em Dom Pedrito é comum o consumo de carne ovina e considerando tal fato, as opções de carnes foram na seguinte ordem de preferência: - primeiro a carne bovina, - segundo a carne de frango, - terceiro a carne ovina, quarta a carne de peixe, e, em último lugar a carne suína. Nessa relação, a maior preferência é pela carne bovina $45,12 \%$, carne de frango 30,77\%, logo após carne suína 29,63\% e carne ovina $22,08 \%$ e de menor preferência pela maioria dos entrevistados carne de peixe $32,5 \%$, como pode ser observado na Figura 02.

Conforme esses dados, a fonte de proteína por ordem de preferência é carne bovina e de frango, sendo que na média estão às carnes ovina e suína e de menor interesse em consumo a carne de peixe, conforme mostra a Tabela 03. Isso reflete as questões culturais, tendo em vista que na região há forte influência da tradição gaúcha, que apresenta consumo considerável de carne bovina, ovina e de frango. Bezerra e Neto (2007) encontrou em pesquisa uma proporção semelhante na microrregião de Campina Grande, $\mathrm{PB}$ com maior consumo destinado à carne bovina $47,75 \%$, frango $21,75 \%$, suína $17,5 \%$ e por fim carne de peixe $13 \%$. Os dados obtidos estão em desacordo com a descrição de Silva (2008) que em estudo sobre consumidores de carne suína na microrregião de Guarabira, PB ao abordar a preferência de carnes demonstrou que a população estudada opta pela carne bovina $64 \%$, seguido pela carne de frango $25 \%$, carne de peixe $8 \%$ e carne suína $3 \%$, entretanto a carne ovina não foi avaliada nessa pesquisa. Conforme Silva (2008) a carne suína é muito apreciada, entretanto perde em preferência se comparada a outras carnes. A questão da cultura local influência consideravelmente a hierarquia de consumo de carnes, o que é explicito por Santos et al. (2011) que revela que 90,6\% dos entrevistados optam pela carne bovina, $80,6 \%$ pela carne de frango, $46,3 \%$ carne de peixe e por fim $40,6 \%$ preferem a carne suína. O autor atribui esses resultados à cultura local, que implica em bovinocultura de corte estabelecida e rios piscosos.

Tabela 03- Estatística demonstrando as preferências por carne bovina, de frango, ovina, de peixe e suína.

\begin{tabular}{l|r|r|r|r|r}
\hline & Mínimo & \multicolumn{1}{|l|}{ Máximo } & \multicolumn{1}{|l}{ Mediana } & \multicolumn{1}{l}{ Média } & Desvio padrão \\
\hline Bovina & 1,00 & 5,00 & 2,00 & 2,27 & 1,48 \\
\hline Frango & 1,00 & 5,00 & 3,00 & 2,78 & 1,34 \\
\hline Ovina & 1,00 & 5,00 & 3,00 & 3,12 & 1,38 \\
\hline Suína & 1,00 & 5,00 & 3,00 & 3,30 & 1,15 \\
\hline Peixe & 1,00 & 5,00 & 4,00 & 3,56 & 1,32 \\
\hline
\end{tabular}

* Quanto mais próximo de 01 maior é a preferência e mais próximo de 05 , menor a preferência de consumo. Fonte: Adaptado de Survey Monkey. 
Os pesquisados foram questionados sobre qual desses alimentos era mais ou menos saudável, na sua opinião. Classificando de 01 a 05 , sendo 01 para carne considerada mais saudável e 05 para aquela menos saudável. Conforme dados analisados, os alimentos considerados mais e menos saudáveis, são respectivamente: carne de peixe $61,25 \%$, carne de frango $49,33 \%$, carne suína $27,16 \%$, carne bovina $36,71 \%$ e carne ovina $39,74 \%$, como constatado na Tabela 04 e na Figura 03.

Tais, informações diferem das encontradas por Kirinus et al (2016) que em seu estudo desenvolvido em Xanxerê, SC, sobre a caracterização do consumidor de carne suína, relatou que os entrevistados quando questionados sobre quais carnes acreditavam ser mais saudáveis responderam, respectivamente, carne de peixe, carne de frango, carne bovina, carne suína e carne ovina. Considerando tais informações o autor do trabalho afirma que os consumidores de carne suína de Xanxerê acreditam que a carne seja gordurosa e pouco benéfica para a saúde, ao contrário do que ocorre no município de Dom Pedrito, RS que a fonte de proteína é considerada mais saudável que a carne bovina e ovina.

A Tabela 04 demonstra em quais tipos de carnes os entrevistados consideram ser mais saudável para seu consumo.

Tabela 04- Estatística demonstrando quais carnes (bovina, frango, ovina, peixe e suína) são consideradas mais saudáveis conforme os entrevistados.

\begin{tabular}{|c|c|c|c|c|c|}
\hline & Mínimo & Máximo & Mediana & Média & Desvio padrão \\
\hline Peixe & 1,00 & 5,00 & 1,00 & 1,96 & 1,43 \\
\hline Frango & 1,00 & 5,00 & 2,00 & 2,80 & 1,10 \\
\hline Suína & 1,00 & 5,00 & 3,00 & 3,20 & 1,36 \\
\hline Bovina & 1,00 & 5,00 & 4,00 & 3,30 & 1,19 \\
\hline Ovina & 1,00 & 5,00 & 4,00 & 3,78 & 1,30 \\
\hline
\end{tabular}

* Quanto mais próximo de 1 maior é a preferência e mais próximo de 5, menor a preferência de consumo. Fonte: Adaptado de Survey Monkey.

Na Figura 03 pode ser observado, segundo a opinião dos entrevistados quais são os tipos de carnes que consideram mais ou menos saudáveis para seus hábitos de consumo. 
Figura 03 - Avaliação conforme os entrevistados sobre quais carnes são mais ou menos saudáveis.

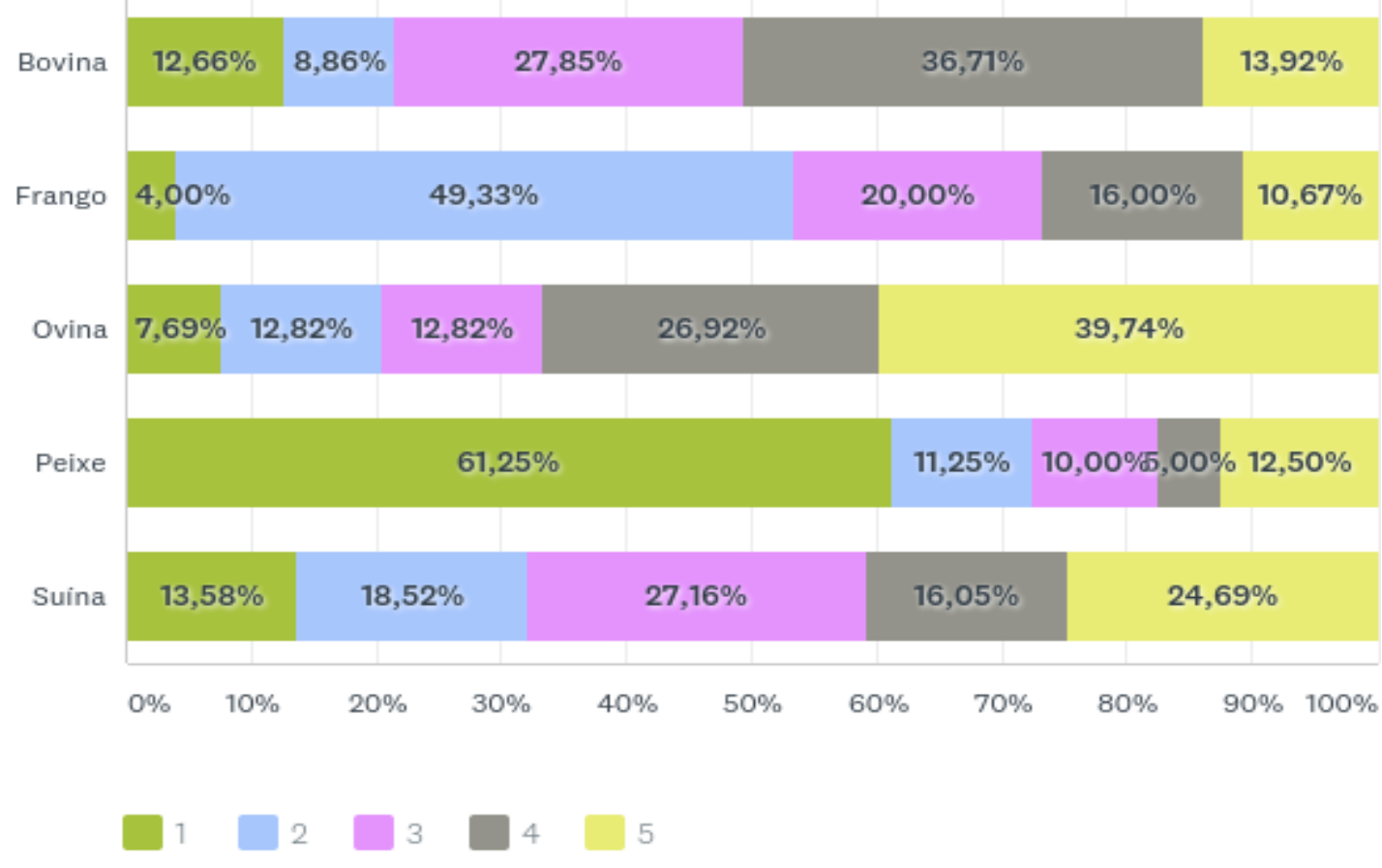

Fonte: Adaptado de Survey Monkey.

Em relação ao consumo de carne suína, apenas $5,81 \%$ dos respondentes relataram possuir qualquer tipo de restrição. Tais dados demonstram que uma parcela pequena dos avaliados apresenta limitação quanto à ingestão desse alimento, isso impossibilita listar e hierarquizar as principais restrições, tendo em vista que não é um número representativo da amostra. Desse pequeno grupo, destaca-se que $40 \%$ dos pesquisados, "acreditam que seja um alimento gorduroso e com altos índices de colesterol".

Tal afirmação faz parte de uma crença sem nenhuma comprovação cientifica, ao contrário disso, tendo em vista que inúmeros trabalhos citam a carne suína como uma fonte de proteína magra e saudável, aplicada inclusive em dietas, esse fato evidencia que foi estabelecida uma opinião no grupo avaliado que consiste em priorizar outras carnes em vez da suína embasado no senso comum. Na Tabela 05 pode ser visualizado as restrições ao consumo da carne suína apontada por $5,81 \%$ dos pesquisados. 
Tabela 05- Consumidores que relataram ter restrições ao consumo de carne suína.

\begin{tabular}{l|ll}
\hline Opções de resposta & Respostas \\
\hline Restrição médica (1) & $0,00 \%$ & 0 \\
\hline Acredita ser um alimento gorduroso e com altos índices de colesterol (2) & $40,00 \%$ & 2 \\
\hline Sabor desagradável (3) & $0,00 \%$ & 0 \\
\hline Alimento de difícil digestão (4) & $20,00 \%$ & 1 \\
\hline Acredita que possa transmitir alguma doença (5) & $0,00 \% \quad 0$ \\
\hline Outro (especifique) (6) & $60,00 \% \quad 3$ \\
\hline
\end{tabular}

Fonte: Adaptado de Survey Monkey.

Outro tópico avaliado foi a frequência de consumo da carne suína, sendo que um percentual considerável dos pesquisados relatou consumir esporadicamente 38,37\%, seguido de semanalmente $30,23 \%$, quinzenalmente $18,6 \%$, mensalmente $11,63 \%$ e diariamente $1,16 \%$. Considerando aqueles que consomem todas ou a cada duas semanas obtém-se um total de $48,83 \%$, o que representa um número razoável de consumidores assíduos. Estando de acordo com Dorneles et al. (2016) que afirmou que o maior consumo da carne suína é mensal. Essa questão, esclarece que mesmo não sendo de maior preferência do restrito grupo de estudo, a carne suína é apreciada de maneira que ocupa espaço na mesa do consumidor.

Quanto ao grau de satisfação dos consumidores, foram incluídas perguntas referentes aos cortes de carne suína disponíveis no mercado, facilidade de encontrar esses cortes, sabor, facilidade de preparo, preço, teor de gordura do alimento, digestibilidade, e se consideram uma fonte de proteína saudável. Isso tendo em vista, que alguns desses fatores poderiam ser considerados limitantes para o consumo, dependendo da resposta dos consumidores pesquisados, sendo que avaliação é de 01 à 05 , sendo 01 considerado totalmente insatisfeito e 05 totalmente satisfeito.

Considerando a satisfação dos consumidores no tocando aos cortes de carne suína disponíveis atualmente no comércio local, a média ponderada de avaliação ficou 3,67, considerado um valor intermediário. Sendo que 2,33\% dos entrevistados relataram estar totalmente insatisfeitos, $9,3 \%$ insatisfeitos, $34,88 \%$ indiferentes, $25,58 \%$ satisfeitos e $27,91 \%$ totalmente satisfeitos, conforme pode ser observado na Figura 04. Fator que permite constatar que os tipos de cortes disponíveis no comércio não impactam significativamente o consumo da proteína, que frente a outros países, é considerado baixo. 
Figura 4 Grau de satisfação dos consumidores quanto aos cortes de carne suína disponíveis no comércio.

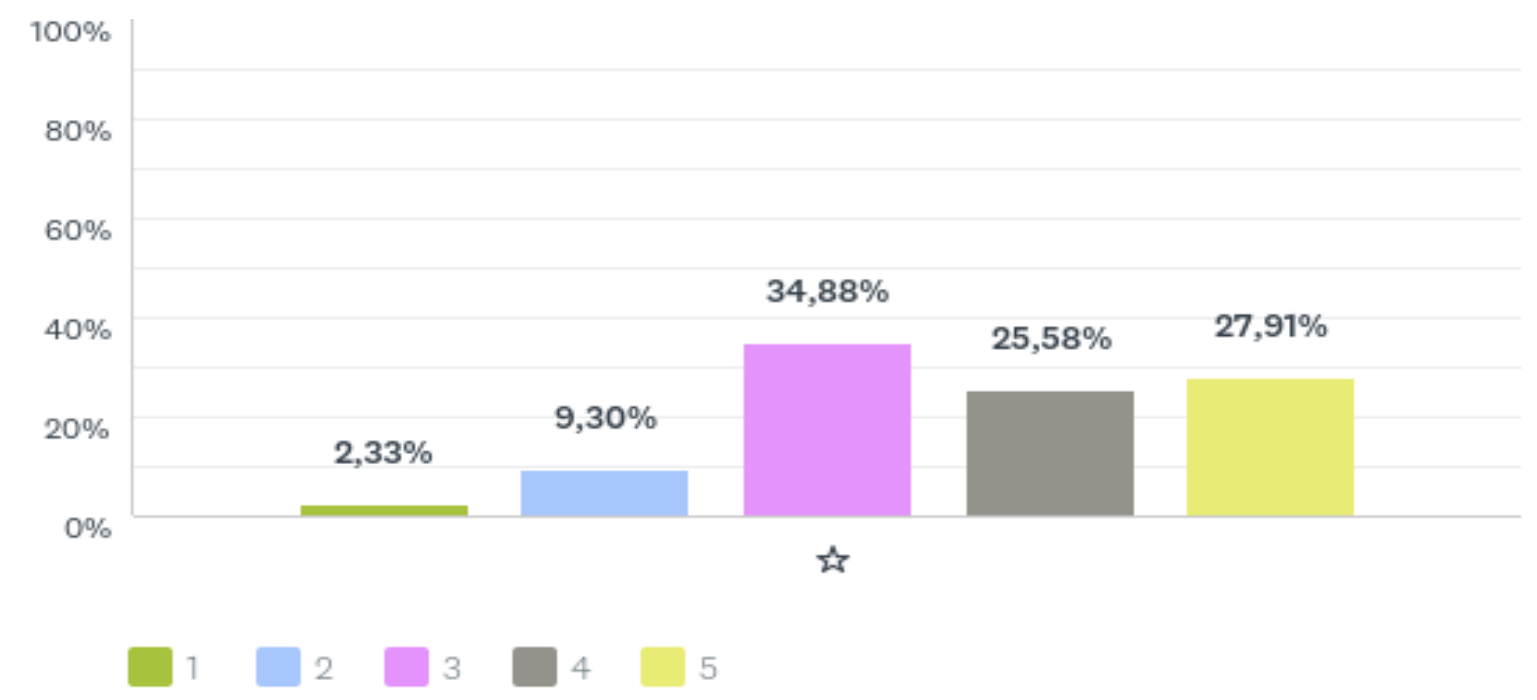

Fonte: Adaptado de Survey Monkey.

Obtiveram-se respostas semelhantes em termos de média ponderada 3,37 quando os entrevistados foram questionados sobre a facilidade de encontrar os cortes desejados. Dos entrevistados 7,14\% informaram estar totalmente insatisfeitos se tratando de encontrar os cortes desejados no comércio, $13,1 \%$ insatisfeitos, enquanto 39,29\% indiferente, $16,67 \%$ satisfeitos e $23,81 \%$ totalmente satisfeitos. Ou seja, em relação a encontrar os cortes desejados no comércio, a maioria dos entrevistados relatou estar indiferente.

Pondera-se que 53,49\% estão satisfeitos e totalmente satisfeitos com os cortes de carnes suínas encontrados no mercado, porém 39,29\% são indiferentes com a facilidade de encontrar os cortes desejados talvez pela falta de conhecimento sobre a variedade dos mesmos ou pela preferência de um corte que sempre esteja disponível nas prateleiras de açougues ou mercados. Estes dados refletem que os consumidores pesquisados não estão à procura de carne suína, pois o hábito de consumo leva a aquisição da carne bovina, ovina e/ou de frango, o que explica o reduzida procura e consumo por carne suína. Destaca-se ainda que a compra pode estar atrelada ao encontrar nas gondolas dos supermercados, estar em oferta, comprar para o final de semana, mas não como habito de consumo, ou seja, a carne suína não é prioridade para os consumidores participantes desta pesquisa.

Outro fator importante abordado após a questão anterior constituiu na opinião do consumidor sobre o sabor da carne suína. Questionamento relevante, tendo em vista que o sabor é normalmente o que leva ao consumo individual. De acordo com os respondentes $2,41 \%$ estão 
totalmente insatisfeitos com o sabor, $10,84 \%$ insatisfeitos, $28,92 \%$ indiferente, $30,12 \%$ satisfeitos e $27,71 \%$ totalmente satisfeitos, tabulando uma média ponderada de 3,7. Tendo isso em vista, a presente pesquisa está em consonância com Bezerra e Neto (2007), Dorneles (2017) e Gervásio (2012) obtendo resultado positivo dos entrevistados ao questionar o sabor da carne suína, sendo essa classificação um dos pontos forte, a fonte de proteína que apresenta a carne suína. Os dados da satisfação dos consumidores de carne suína em relação ao seu sabor podem ser observados na Figura 05.

Figura 05- Grau de satisfação do consumidos quando ao sabor da carne suína.

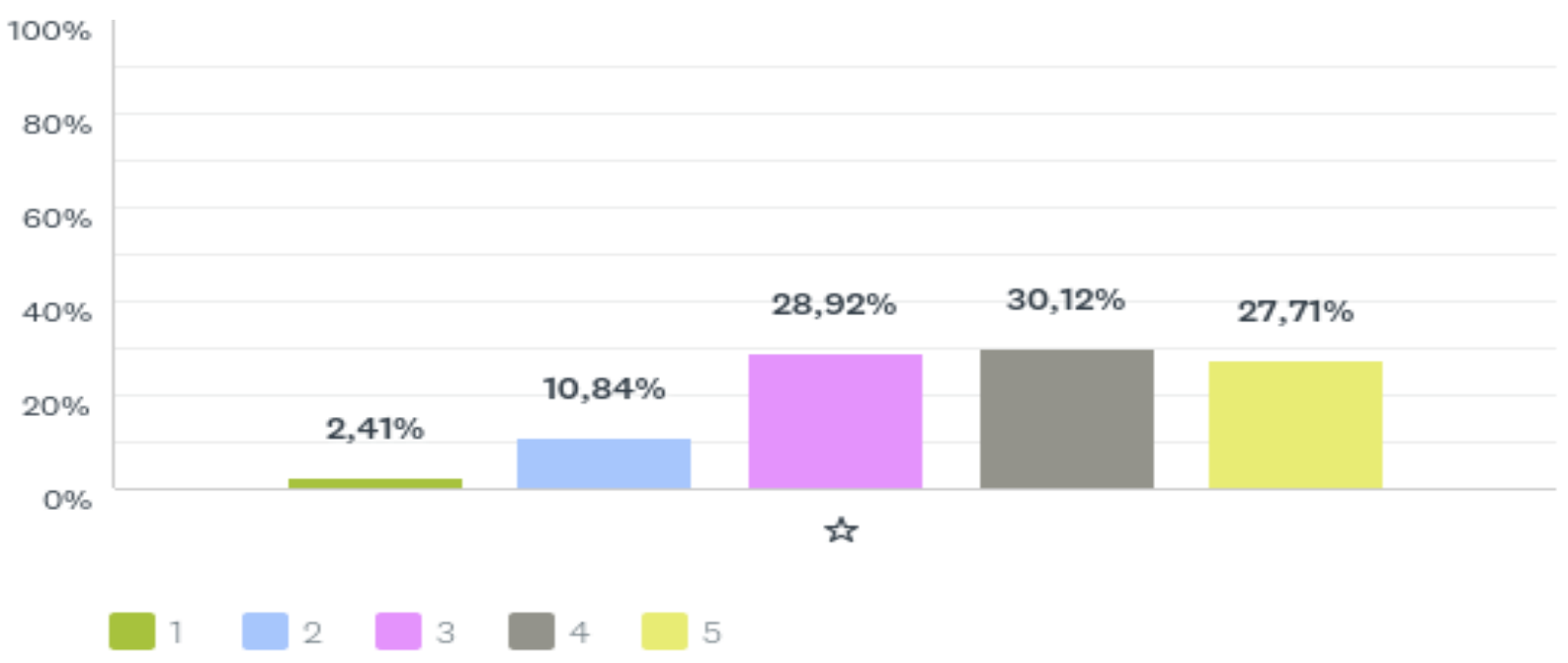

Fonte: Adaptado de Survey Monkey.

Na Figura 06 e demonstrado o grau de satisfação dos consumidores em relação a facilidade de preparo da carne suína.

Figura 06- Grau de satisfação dos consumidores em relação facilidade de preparo da carne suína.

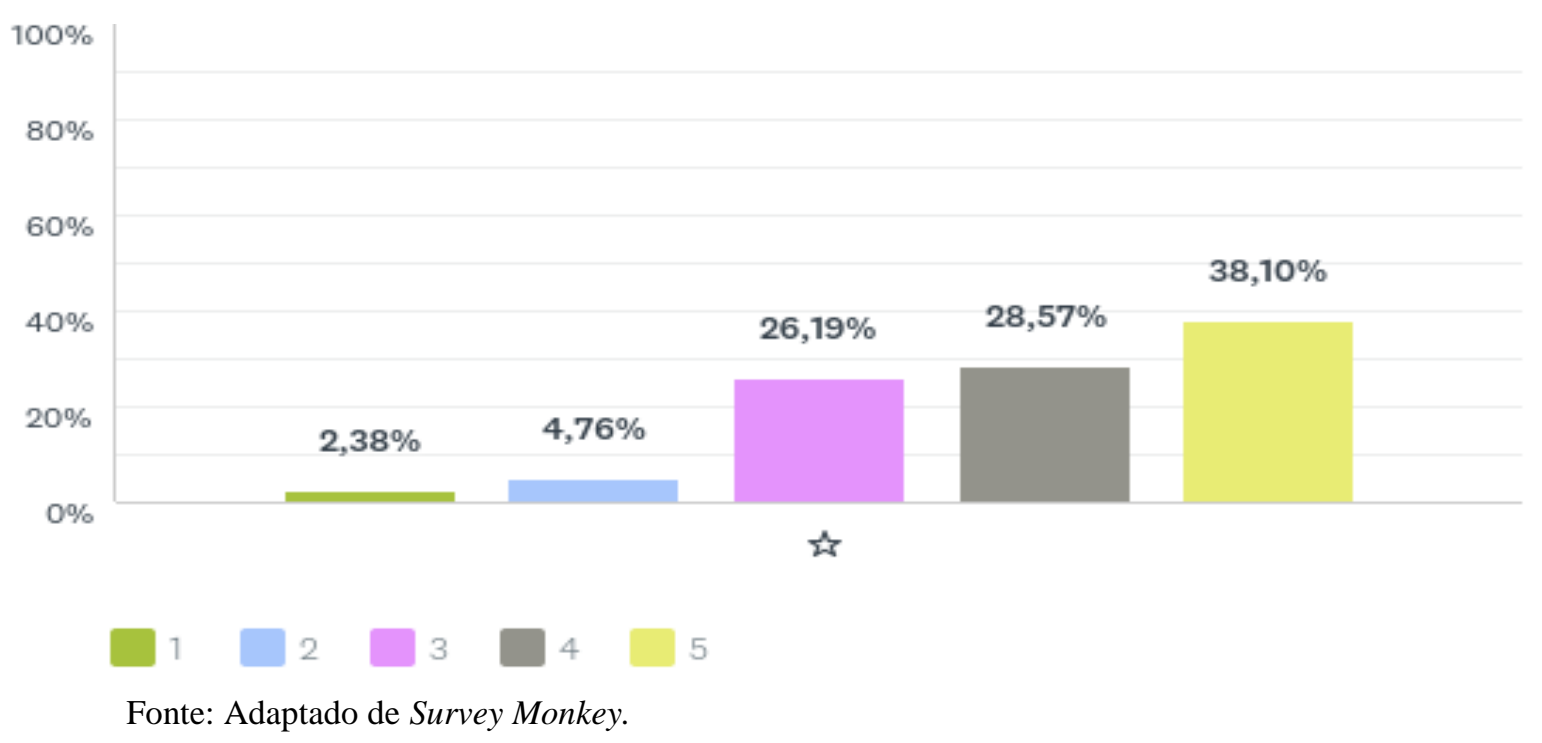


Pode-se observar que em relação à facilidade de preparo, houve um retorno de 2,38\% dos entrevistados informando estar totalmente insatisfeitos, 4,76\% insatisfeitos, $26,19 \%$ indiferentes, $28,57 \%$ satisfeitos e $38,1 \%$ totalmente satisfeitos, totalizando uma média ponderada de 3,95. Estes dados mostram que satisfeitos representam 66,67\% dos pesquisados, ou seja, mais da metade dos entrevistados. Tais dados também demonstram que a carne suína é satisfatória em relação à facilidade de preparo frente ao grupo pesquisado, estando de acordo com Gervásio (2012), que relatou que um dos fatores que levam ao consumo desse alimento é o preparo fácil.

Referente ao preço da carne suína, a maioria dos respondentes relatou estar indiferente totalizando $42,35 \%$, sendo $17,65 \%$ satisfeitos e $16,47 \%$ totalmente satisfeitos, enquanto que $5,88 \%$ informaram estar totalmente insatisfeitos e 17,65\% insatisfeitos. Estes dados estão de acordo com Gervasio (2012), em seu estudo o autor explica que maioria dos entrevistados concorda que a carne suína é fácil de encontrar e possui um preço justo, o que pode ser fator determinante para o seu consumo. Conforme Dorneles et al. (2016) entre os principais motivos de consumo da carne suína está o sabor, preço acessível e facilidade de preparo, estando assim de acordo com o autor. Considerando ainda que segundo Bezerra et al. (2007) o ponto forte e maior razão de consumo carne suína é o seu sabor.

Já, tratando do teor de gordura da carne suína, um total de 15,3\% dos respondentes relatou estar insatisfeitos, $29,41 \%$ indiferentes e 55,3\% satisfeitos, o que em parte comprova a teoria citada anteriormente de que apenas pessoas com pouco acesso a informações e instrução permanecem com a crença de que carne de suíno é gordurosa.

Quanto à disgestibilidade 3,61\% dos entrevistados estão totalmente insatisfeitos, $10,84 \%$ insatisfeitos, $28,92 \%$ indiferentes, $30,12 \%$ satisfeitos e $26,51 \%$ totalmente satisfeitos. Tendo em vista o grau de satisfação obtido em relação aos fatores acima citados, os dados estão em desacordo com o trabalho de Bezerra et al. (2007) que cita o baixo consumo da carne suína como consequência de ser um alimento de difícil digestão e gorduroso, conforme os entrevistados. Mas novamente, questões atreladas a digestibilidade dependem da origem do alimento, ou seja, o método de produção e também a crenças que devem ser desfeitas no tocando à composição nutricional dessa fonte de proteína.

Sobre o questionamento da carne suína ser saudável, o grau de satisfação dos consumidores evidenciou $7,06 \%$ dos respondentes como insatisfeitos, 30,59\% indiferentes 
mesmo percentual encontrado para aqueles que relataram estar satisfeitos e por fim $31,76 \%$ totalmente satisfeitos, como pode ser observado na Figura 07, abaixo.

Fato que permite seguir a mesma linha de raciocínio sobre a falta de conhecimento baseado no senso comum que estabeleceu uma teoria negativa sobre a carne de suíno que era produzida de maneira extensiva e resultava em um produto diferente do encontrado atualmente. É possível constatar isso, tendo em vista que a maior parte dos entrevistados possui nível superior, isso permite pressupor que são pessoas com maior grau de instrução e que buscam por informações provenientes dos alimentos que consomem, de uma maneira geral, e por isso os resultados obtidos não são influenciados por crenças, como as descritas em outros trabalhos.

Figura 07- Grau de satisfação quanto à carne suína ser salubre.

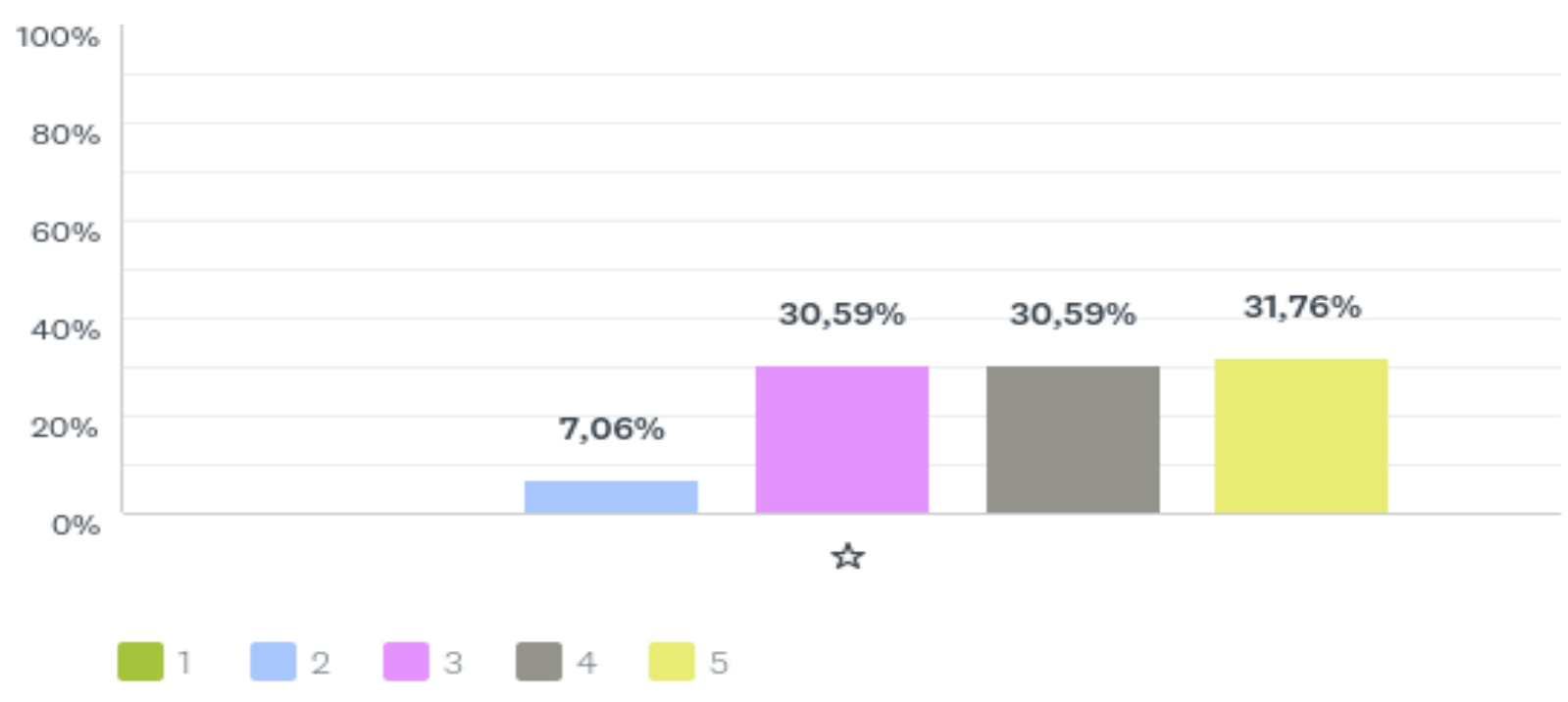

Fonte: Adaptado de Survey Monkey.

\section{CONSIDERAÇÕES FINAIS}

Após análise e discussão dos dados obtidos através dos questionários aplicados, foi possível avaliar que o consumo de carne suína em um grupo restrito de consumidores do município de Dom Pedrito, RS, não é influenciado por restrições, tais como: ser um alimento com alto teor de gordura e de difícil digestão. O grupo pesquisado foi composto principalmente por indivíduos com nível superior e pós-graduação, e consequentemente pessoas que possuem maior discernimento e não se baseiam em teorias sem bases científicas para expressarem suas ideias. Em relação a faixa etária, a maior parte compreende entre 21 à 39 anos, o que elucida o 
fato de serem pessoas mais jovens e menos atreladas a crenças antigas sobre o consumo de carne suína.

Destaca-se que os fatores que influenciam o consumo de carne suína é encontrar o corte preferido no local de venda, mas não representa uma busca preferencial do consumidor, pois a carne bovina e ovina está em primeiro lugar. Maciez, sabor e facilidade de preparo são considerados importantes pelos consumidores pesquisados, mas não é preponderante para a realização da compra. Percebe-se que a compra é esporádica, encontrando maior expressividade no consumo mensal e quinzenal, ou seja, representa a compra para consumir no fim de semana. A compra demonstra estar mais atrelada ao encontrar esporadicamente o corte de sua preferência nos supermercados, em promoção do que sair para adquirir o produto. O churrasco do final de semana tem que ter carne bovina ou ovina, mas não necessariamente carne suína. $O$ sabor da carne e a facilidade de preparo são pontos positivos para o consumo da carne suína, mas não é preponderante para consumi-la diariamente.

Com os dados foi possível avaliar que o consumo de carne suína no grupo pesquisado é influenciado por dois fatores: o hábito de consumo e forte influência da cultura local. Tendo em vista que não há o habito de consumir carne suína com frequência semanalmente, talvez por não possuir granjas próximas que permitiriam maior disponibilidade de produto e cortes específicos. Isso sem contar a cultura local que privilegia a carne bovina e ovina, consequência da forte pecuária da região e produtos de qualidade diferenciada. É possível que se houvesse maior diversidade de cortes de carne suína e conhecimento dos consumidores sobre o modo de preparo, para que não seja uma carne com aspecto seco e sabor razoável, o consumo seria maior.

Foi possível avaliar também, que a carne suína ficou na média na maioria dos fatores abordados, como: facilidade de preparo, sabor, cortes disponíveis, entre outros. Isso leva a conclusão de que a carne suína é pouco consumida pela falta de conhecimentos sobre seu preparo e cortes nobres, considerando que em diversos locais trata-se de uma carne muito apreciada e saborosa, saindo dos padrões médios de consumo.

\section{REFERENCIAS}

ASSOCIAÇÃO BRASILEIRA DE CRIADORES DE SUÍNOS (ABCS). Produção de suínos bate recorde. 215. Disponível em: <http://www.abcs.org.br/informativo-abcs/2213-producaode-suinos-bate-recorde> Acesso em: 1/05/17. 
ASSOCIAÇÃO BRASILEIRA DE PROTEÍNA ANIMAL (ABPA). avicultura e suinocultura do Brasil: Produção e Exportação; Previsões para 215 e 216. Disponível em: http://abpabr.com.br/noticia/avicultura-e-suinocultura-do-brasil-producao-e-exportacao-previsoes-para215-e-216-1478 Acesso em: 18/05/17.

ASSOCIAÇÃO BRASILEIRA DE PROTEÍNA ANIMAL (ABPA). História da Suinocultura no Brasil. Disponível em: http://abpa-br.com.br/setores/suinocultura Acesso em: 03/05/17. ASSOCIAÇÃO BRASILEIRA DE PROTEÍNA ANIMAL (ABPA). Relatório Anual 216. Disponível em: http://abpabr.com.br/storage/files/versao_final_para_envio_digital_1925a_final_abpa_relatorio_anual_2 16_portugues_web1.pdf Acesso em: 19/06/17.

ASSOCIAÇÃO BRASILEIRA DO AGRONEGÓCIO (ABAG). Carne bovina argentina está de volta ao jogo. 215. Acesso em 18/06/17. Disponível em: www.abag.com.br/sala_imprensa/interna/abag-carne-bovina-argentina-esta-de-volta

BAKER, G. Strategic Implications of Consumer Food Safety Preferences, International Food and Agribusiness Management Reviews, v.1, n.4.p.451-463, 1998.

BEZERRA, J. M. M.; et. al. Caracterização do Consumidor e do Mercado da Carne Suína na Micro-Região de Campina Grande, Estado da Paraíba. Ciência Animal Brasileira, v. 8, n. 3, p. 485-493, jul./set. 2007.

BUSO, G. (2000). Análise do perfil do consumidor de carne bovina na cidade de São Paulo. São Carlos (SP). Dissertation, São Carlos: Departamento de Engenharia de Producão, Universidade Federal de São Carlos - UFSCar.

CAVALCANTE NETO, A. Caracterização, avaliação e estratégias de desmistificação dos consumidores e do mercado da carne suína no Estado da Paraíba. 12 f. Trabalho de conclusão de curso (Graduação em Zootecnia) - Centro de Ciências Agrárias, Universidade Federal da Paraíba, Areia, Paraíba, 2003.

CONFEDERAÇÃO DA AGRICULTURA E PECUÁRIA DO BRASIL (CNA). Ativos Suinocultura. 215. Ed. 1. Disponível em:

http://www.canaldoprodutor.com.br/sites/default/files/Ativos-Suinocultura-n1.pdf Acesso em: 18/05/17.

DAVIS, C. G., \& LIN, B. H. (2005). Factors affecting US pork consumption. US Department of Agriculture, Economic Research Service.

e derivados em Belo Horizonte. Arquivo Brasileiro de Medicina Veterinária e Zootecnia, v. 58, p. 251-256, 2006.

FARIA, I.G.; FERREIRA, J.M.; GARCIA, S.K. Mercado consumidor de carne suína e derivados em Belo Horizonte. Arquivo Brasileiro de Medicina Veterinária e Zootecnia, v. 58, n. 2, p. 251-256, 2006.

FLANDRIN, JL.; MONTANARI, M. História da Alimentação. 3 ed. São Paulo. Estação Liberdade, 1998. 
GERHARDT, T.; SILVEIRA, D. Métodos de Pesquisa. Curso de Graduação Tecnológica Planejamento e Gestão para o Desenvolvimento Rural da SEAD/UFRGS. Porto Alegre:

Editora da UFRGS, 2009.

GERVÁSIO, E. Carne suína: Fatores determinantes para o consumo. Curitiba. Monografia. Universidade Federal do Paraná. 31 p. 212.

GOLDENBERG, M. A arte de pesquisar. Rio de Janeiro: Record, 1997.

HAUTRIVE, T. P.; MARQUES, A. C.; KUBOTA, E. H. Avaliação da composição centesimal colesterol e perfil de ácidos graxos de cortes cárneos comerciais de avestruz, suíno, bovino e frango. Alimentos e Nutrição Araraquara, v. 23, p. 327-334, 212.

JORGE, R.; SLONGO, L. Hábitos de consumo e nível de satisfação do consumidor de carne bovina do município de Dom Pedrito-RS. Dissertação. UFRGS. 71 p. 201.

KIRINUS, J.; BENEDETTI, M.; TÉO, A.; PAVLIK, W.; TAFFAREL, G.; BELMONTE, C.; DÖRR, A. Caracterização do consumo de carne suína da população de Xanxerê, Santa Catarina, Brasil. Revista Eletrônica em Gestão, Educação e Tecnologia Ambiental, Santa Maria, v.20, n. 1, p. 233-240. 216.

MAGNONI, D.; PIMENTEL, I. A importância da carne suína na nutrição humana. São Paulo: UNIFEST, 2007.

MARÇAL, D.; ABREU, R. CHEUNG, T. KIEFER, C. Consumo da carne suína no brasil: aspectos simbólicos como determinantes dos comportamentos. Rev. Agro. Amb., v. 9, n. 4, p. 989-1005. 216.

MONTOSSI, F., CAZZULI, F., BRITO, G., REALINI, C., LUZARDO, S., ROVIRA, P., \& FONT-I-FURNOLS, M. (218). The challenges of aligning consumer preferences and production systems: Analysing the case of a small beef meat exporting country. International Journal of Agricultural Policy and Research, 6(9), 144-159.

MURATA, L.S.; STEIN, M.R.; REZENDE, M.J.M.; ALMEIDA, M.N. Perfil do consumidor da carne suína no Distrito Federal. Congresso de suinocultura do nordeste, 1., Anais. p.105106. 202.

PRESS AGROBUSINESS. Carne de porco: saudável, mas ainda pouco apreciada. 215. Disponível em: www.revistapress.com.br/agrobusiness/?p=36 Acesso em: 20/06/17.

REGMI, A. (201). Changing structure of global food consumption and trade: An introduction. In Economic research service/United States Department of Agriculture.

www.ers.usda.gov/publications/wrs11/wrs11h.pdf. Accessed: October 2005.

RODRIGUES, R. Brasil consome menos carne suína do que produz. Por puro preconceito. 216. Acesso em: 22/06/17. Disponível em: https://www.suinoculturaindustrial.com.br/imprensa/brasil-consome-menos-carne-suina-doque-produz-por-puro-preconceito/2161121-154243-k114 
ROPPA, L. A suinocultura em números. Seminário internacional de suinocultura, 1., 1996, São Paulo. Anais. São Paulo: Animal World. p. 1-16. 1996.

SANTOS, B.: AURÉLIO, M. Comportamento do Consumidor: Conceitos e Casos. $9^{\circ}$ Ed. Porto Alegre: Bookman, 213.

SANTOS, T.; CAPPI, N.; SIMÕES, A.; SANTOS, V.; PAIANA, D.; GARCIA, E.

Diagnóstico do perfil do consumidor de carne suína no município de Aquidauana-MS. Rev. Bras. Saúde Prod. An., Salvador, v.12, n.1, p.1-13. 211.

TRIVIÑOS, A. N. S. Introdução à pesquisa em ciências sociais: a pesquisa qualitativa em educação. São Paulo: Atlas, 1987. 